Int. J. Electrochem. Sci., 16 (2021) Article ID: 21075

International Journal of

ELECTROCHEMICAL

SCIENCE

$\underline{\text { www.electrochemsci.org }}$

\title{
An Improved Rainflow Algorithm Combined with Linear Criterion for the Accurate Li-ion Battery Residual Life Prediction
}

\author{
Junhan Huang ${ }^{1}$, Shunli Wang ${ }^{1, *}$, Wenhua Xu ${ }^{1}$, Carlos Fernandez, Yongcun Fan ${ }^{1}$, Xianpei Chen ${ }^{1}$ \\ ${ }^{1}$ School of Information Engineering, Southwest University of Science and Technology, Mianyang \\ 621010, China; \\ ${ }^{2}$ School of Pharmacy and Life Sciences, Robert Gordon University, Aberdeen AB10-7GJ, UK. \\ *E-mail: wangshunli@swust.edu.cn
}

doi: $10.20964 / 2021.07 .29$

Received: 9 February 2021 / Accepted: 3 April 2021 / Published: 31 May 2021

\begin{abstract}
Li-ion battery health assessment has been widely used in electric vehicles, unmanned aerial vehicle and other fields. In this paper, a new linear prediction method is proposed. By weakening the sensitivity of the Rainflow algorithm to the peak data, it can be applied to the field of battery, and can accurately count the number of Li-ion battery cycles, and skip the cumbersome link of parameter identification. Then, a linear criterion is proposed based on the idea of proportion, which makes the life prediction of Li-ion battery linear. Under the verification of multiple sets of data, the prediction error of this method is kept within $2.53 \%$. This method has the advantages of high operation efficiency and simple operation, which provides a new idea for battery life prediction in the field of electric vehicles and aerospace.
\end{abstract}

Keywords: Li-ion battery; state of charge; unscented Kalman filtering; Rainflow; linear prediction criterion

\section{FULL TEXT}

(C) 2021 The Authors. Published by ESG (www.electrochemsci.org). This article is an open access article distributed under the terms and conditions of the Creative Commons Attribution license (http://creativecommons.org/licenses/by/4.0/). 